OPEN ACCESS

Edited by: Alexandr Bazhin,

LMU Munich University Hospital, Germany

Reviewed by:

Denis Soulieres,

University of Montreal Hospital Centre (CRCHUM), Canada

Paolo Boscolo-Rizzo,

University of Trieste, Italy

*Correspondence:

Xin Jiang

jiangx@jlu.edu.cn

${ }^{+}$These authors have contributed equally to this work

Specialty section:

This article was submitted to

Cancer Immunity

and Immunotherapy,

a section of the journal

Frontiers in Immunology

Received: 11 January 2021 Accepted: 31 May 2021

Published: 08 July 2021

Citation:

Wang $H$, Zhao $Q$, Zhang Y, Zhang Q, Zheng Z, Liu S, Liu Z,

Meng L, Xin $Y$ and Jiang $X$ (2021) Immunotherapy Advances in Locally Advanced and Recurrent/Metastatic

Head and Neck Squamous Cell

Carcinoma and Its Relationship

With Human Papillomavirus.

Front. Immunol. 12:652054.

doi: 10.3389/fimmu.2021.652054

\section{Immunotherapy Advances in Locally Advanced and Recurrent/Metastatic Head and Neck Squamous Cell Carcinoma and Its Relationship With Human Papillomavirus}

\author{
Huanhuan Wang ${ }^{1,2,3 \dagger}$, Qin Zhao ${ }^{1,2,3 \dagger}$, Yuyu Zhang ${ }^{1,2,3}$, Qihe Zhang ${ }^{1,4}$, \\ Zhuangzhuang Zheng ${ }^{1,2,3}$, Shiyu Liu ${ }^{1,2,3}$, Zijing Liu ${ }^{1,2,3}$, Lingbin Meng ${ }^{5}$, Ying Xin ${ }^{4}$ \\ and Xin Jiang ${ }^{1,2,3 *}$ \\ ${ }^{1}$ Department of Radiation Oncology, The First Hospital of Jilin University, Changchun, China, 2 Jilin Provincial Key Laboratory \\ of Radiation Oncology \& Therapy, The First Hospital of Jilin University, Changchun, China, ${ }^{3}$ National Health Commission \\ (NHC) Key Laboratory of Radiobiology, School of Public Health, Jilin University, Changchun, China, ${ }^{4}$ Key Laboratory of \\ Pathobiology, Ministry of Education, Jilin University, Changchun, China, ${ }^{5}$ Department of Hematology and Medical Oncology, \\ Moffitt Cancer Center, Tampa, FL, United States
}

Head and neck cancer (HNC) is the sixth most common malignancy worldwide; head and neck squamous cell carcinoma (HNSCC) account for the most cases of HNC. Past smoking and alcohol consumption are common risk factors of HNSCC; however, an increasing number of cases associated with human papillomavirus (HPV) infection have been reported in recent years. The treatment of HNSCC is integrated and multimodal including traditional surgery, radiotherapy, chemotherapy, and targeted therapy. Since pembrolizumab was approved in 2016, an increasing number of studies have focused on immunotherapy. However, not all of HNSCC patients have a better outcome on immunotherapy. Immunotherapy has been reported to be more effective in HPVpositive patients, but its molecular mechanism is still unclear. Some researchers have proposed that the high proportion of infiltrating immune cells in HPV-positive tumors and the difference in immune checkpoint expression level may be the reasons for their better response. As a result, a series of individualized immunotherapy trials have also been conducted in HPV-positive patients. This paper summarizes the current status of HNSCC immunotherapy, individualized immunotherapy in HPV-positive patients, and immune differences in HPV-positive tumors to provide new insights into HNSCC immunotherapy and try to identify patients who may benefit from immunotherapy.

Keywords: head and neck squamous cell carcinoma, immunotherapy, human papillomavirus, immune-checkpoint inhibitors, immune characteristics 


\section{INTRODUCTION}

Head and neck cancer (HNC) is the sixth most common malignancy worldwide, with approximately 800,000 new cases and 400,000 deaths annually (1), of which head and neck squamous cell carcinoma (HNSCC) account for $>90 \%$ cases. Past smoking and alcohol consumption are major risk factors of HNSCC. However, the incidence of human papillomavirus (HPV)-associated HNSCC has been increasing recently $(2,3)$, especially HPV-associated oropharyngeal squamous cell carcinoma (OPSCC) $(4,5)$. Of the $>200$ subtypes of HPV have been identified (6), HPV16 is the most closely related to the occurrence and development of HNSCC (7). The prevalence of HPV16 is $>80 \%$ among HPV-infected OPSCC patients $(4,8)$. E6 and E7, the two major oncogenic proteins of HPV, can downregulate the tumor suppressor factors TP53 and RB (9, 10 ), thereby mediating the expression cytokines, leading to immune escape (11), downregulating the interferon pathway, and resulting in an immune-privileged tumor state (12). The above mechanism is the main mechanism underlying HPVdriven HNSCC. Although HPV-positive tumors are more advanced, have a greater burden of disease, but patients with such tumors generally have higher survival rates (13-15), possibly because they have a better treatment response (16).

The treatment of HNSCC is integrated and multimodal including surgery, radiotherapy, chemotherapy and so on (1719). Patients with early-stage tumors are often considered curable. However, most patients have the advanced disease, often involving the lymph nodes $(20,21)$. The overall survival rates of patients with advanced disease remain low and most patients relapse within 3-5 years, despite the use of a platinumbased chemotherapy of treatments (22). Nevertheless, combination therapy has been the mainstay of treatment for decades until 2016, when a new immunotherapy was introduced, ushering a new era for HNSCC therapy. Programmed death receptor-1 (PD-1) inhibitors were approved in 2016 for recurrent/metastatic (R/M) HNSCC that progresses after chemotherapy failure. Subsequently, studies on immunecheckpoint inhibitors (ICs) against PD-1, programmed death receptor ligand-1 (PD-L1), and cytotoxic T lymphocyteassociated protein-4 (CTLA-4) were performed (23-25). To date, five PD-1 inhibitors for HNSCC have been developed to the second line of therapy, with the most comprehensive data available for pembrolizumab (KEYNOTE-012 trial) and nivolumab (CheckMate-141 trial) $(26,27)$. Currently, these two PD-1 inhibitors have been approved by the Food and Drug Administration (FDA) for the treatment of platinumresistant $\operatorname{HNSCC}(26,27)$. ICs have achieved good efficacy in some HNSCC, indicating that targeted immune system therapy can achieve clinical benefits in HNSCC patients $(28,29)$. However, most patients show primary resistance, and it is unclear which patients with HNSCC will benefit the most from immunotherapy (30). Studies have shown that immune differences in HPV-positive HNSCC patients may make immunotherapy more effective (29). Hence, studies on immunotherapy in HPV-positive HNSCC have also been conducted.
This article aimed to review the progress of immunotherapy for HNSCC, and to further elucidate the differences between HPVpositive and HPV-negative of immune levels, and the molecular mechanisms underlying the different immunotherapy effects.

\section{IMMUNOTHERAPY IN HNSCC}

The Cancer Genome Atlas (TCGA) data shows that HNSCC is the most immune-active tumor tissue after lung adenocarcinoma and renal cell carcinoma (31-33). The occurrence and progression of HNSCC is associated with serious immune deficiency, including immune cell dysfunction, decreased cytokine secretion, and antigen presentation defects $(34,35)$. Therefore, targeting the immune system is expected to become a new treatment strategy for HNSCC (36). The interactions between tumor cells and the immune system in HNSCC is shown in Figure 1. This study aimed to review immunotherapy for HNSCC from these aspects: immune checkpoint and immune microenvironment.

Immune checkpoints are part of the protein-ligand receptor system that controls $\mathrm{T}$ cell activation. Therefore, the application of ICs to block the role of immune checkpoints can promote the release of $\mathrm{T}$ cells, increase the antitumor response, and, thus, enhance tumor cell clearance and immune monitoring. PD-1 is a transmembrane protein of the CD28 family of T cell costimulatory receptors, which is expressed in a variety of immune cells, especially in cytotoxic T cells $(37,38)$. PD-1 binds to its ligands (PD-L1 and PD-L2), reducing $\mathrm{T}$ cell activity and maintaining immune tolerance (39). Therefore, the binding of monoclonal antibodies to PD-1 or PD-L1 can block the inhibitory function of immune checkpoints on $\mathrm{T}$ cells to restore the $\mathrm{T}$ cell immune response. Pembrolizumab (KEYNOTE-012 trial), the first reported PD-1 inhibitor for R/M HNSCC, had a response rate of $18 \%$ (26). This trial supported further study of pembrolizumab as anticancer therapy for HNSCC. Subsequently, the KEYNOTE-055 trial also confirmed this finding (40). Based on these findings, pembrolizumab received accelerated FDA approval in 2016 for the treatment of HNSCC. The KEYNOTE-040 was the randomized, open-label, phase III study, which included 495 patients with refractory HNSCC. The results showed that the median survival time in the pembrolizumab and standard treatment groups was 8.4 and 6.9 months, respectively. In addition, pembrolizumab group had fewer treatment-related adverse events of grade 3 and worse than standard treatment group (30). The results suggest that pembrolizumab may be monotherapy and a part of combination therapy for HNSCC. Subsequently, a clinical trial using pembrolizumab in combination with chemotherapy was conducted. The KEYNOTE-048 trial compared the effectiveness of pembrolizumab alone and pembrolizumab combined with chemotherapy to traditional chemotherapy in patients who relapsed 6 months after standard treatment, which results showed pembrolizumab with chemotherapy improved overall survival versus chemotherapy (13 months vs. 10.7 months, HR 0.77, p=0.0034) (28). Thus, pembrolizumab alone and pembrolizumab in combination with platinum and 5-fluorouracil can be used as an appropriate firstline treatment for R/M HNSCC. In view of this, more clinical 


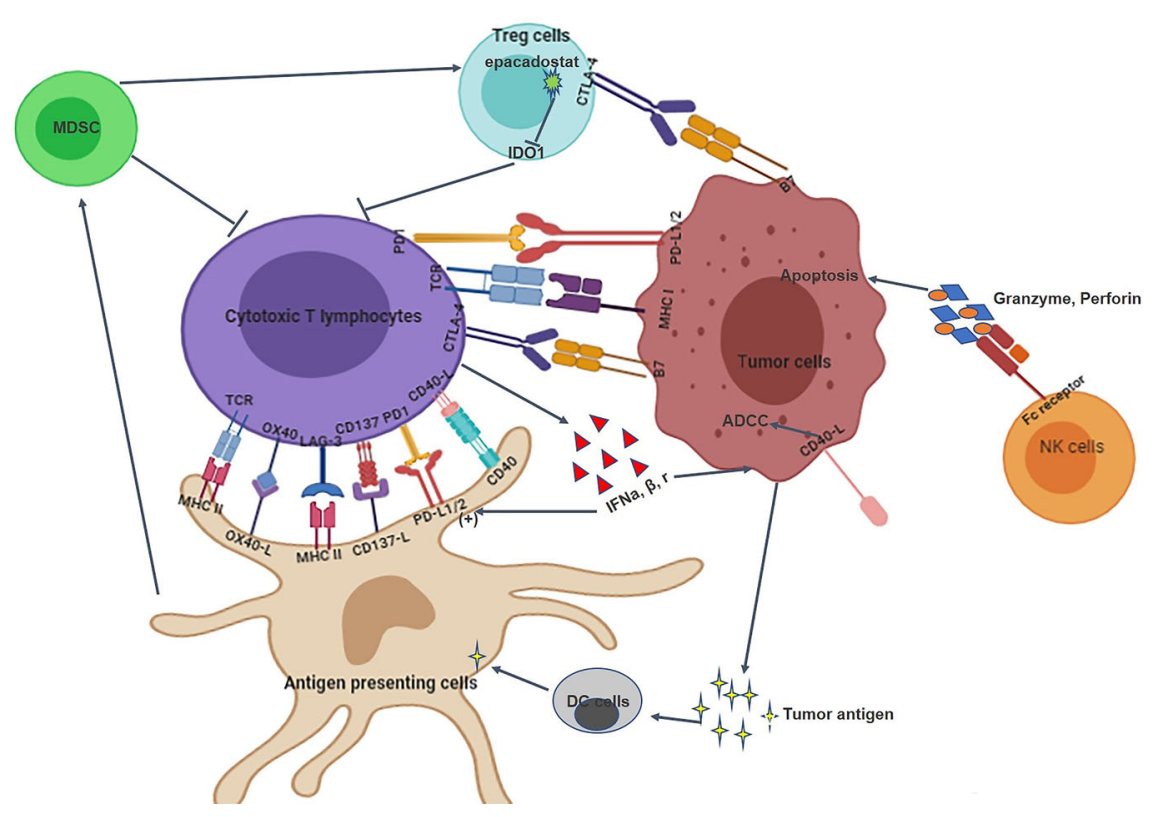

FIGURE 1 | The interaction between HNSCC tumor cells and the immune system. 1) The immune system of HNSCC tumor tissues includes immune cells, immune checkpoints, and immune microenvironment; 2). Immune checkpoints such as PD-1/PD-L1 and CTLA-4/B7 can inhibit the proliferation and infiltration of cytotoxic T lymphocytes; 3) MDSC, Treg cells, NK cells and cytotoxic T lymphocytes are involved in the elimination of tumor cells; 4) Tumor cells and immune cells can also interact with each other through cytokines.

trials are currently underway, including a comparison of pembrolizumab plus radiotherapy with chemotherapy (NCT02641093). In addition, studies have compared the efficacy of pembrolizumab and the oncolytic virus Talimogene laherparepvec (NCT02626000) and the use of pembrolizumab in combination with other agents such as colony-stimulating factor receptor kinase inhibitors (NCT02452424) and histone deacetylase inhibitors (NCT02538510).

CheckMate 141 was the first reported phase III clinical trial of a PD-1 inhibitor, which was designed to compare the efficacy of nivolumab to that the conventional regimen in R/M HNSCC (27). The results showed that nivolumab was significantly better than traditional chemotherapy, with an increased median survival time of 2.4 months (7.5 months vs. 5.1 months), a $20 \%$ higher 1 -year survival rate (36\% vs. $16 \%)$, and a significantly reduced risk of severe adverse reactions (27). Hence, FDA approved nivolumab as a second-line treatment for $\mathrm{R} / \mathrm{M}$ HNSCC in 2016. In addition, nivolumab in combination with lirilumab, an NK cell-targeted antibody, showed an objective response rate of $24 \%$, and a tumor load reduction of $80 \%$ in patients with HNSCC $(41,42)$. In NCT02426892, nivolumab in combination with the HPV vaccine (ISA101) showed significant activation of $\mathrm{T}$ cells and better anti-tumor response in patients with OPSCC (43). In addition, ongoing clinical studies have been assessing the effectiveness of nivolumab in combination with other regimens, such as nivolumab combined with stereotactic radiotherapy (SBRT) (NCT02684253).

Clinical trials of PD-L1 antibodies are also widely underway, such as durvalumab, atezolizumab, and avelumab. A phase II clinical study showed a $16 \%$ response rate and a 33\% 1 -year survival rate for 100 patients administered durvalumab (44). In addition, several clinical studies of durvalumab monotherapy are ongoing (such as NCT02207530 and NCT02827838). The phase I clinical study of atezolizumab showed an effective rate of $22 \%$ (45).The phase I clinical trial that evaluate the efficacy of avelumab and CD137 agonists (NCT02554812) is underway.

In addition to PD-1 and PD-L1 inhibitors being applied on HNSCC, CTLA-4 is also an important immune checkpoint. Tremelimumab is an antibody to CTLA-4, CONDOR and EAGLE trial concluded that durvalumab alone or in combination with tremelimumab in patients with R/M HNSCC does not show a significant difference in efficacy $(46,47)$. Ipilimumab is also a monoclonal antibody against CTLA-4. Clinical trials of ipilimumab and cetuximab combined with IMRT in patients with advanced HNSCC are ongoing (NCT01860430 and NCT01935921). In addition, clinical trials of CD276 and OX40 as new immunotherapeutic targets are also being carried out widely, such as NCT02381314, NCT02274155, etc.

In addition, other immunotherapy drugs have been studied successively, such as the indoleamine 2,3-dioxygenase 1 (IDO1) inhibitors navoximod and epacadostat. IDO1, a rate-limiting enzyme converted to kynurenine by tryptophan, plays an immunosuppressive role in tumor immune microenvironments $(48,49)$. In previous studies, upregulation of IDO1 inhibited the function of antitumor T cells (50) and high IDO1 expression was associated with poor prognosis (51). IDO1 inhibitor can restore $\mathrm{T}$ lymphocyte function, resulting in tumor microenvironment immunogenicity (52). In a phase I clinical trial, navoximod 
showed good efficacy in $36 \%$ patients (53). KEYNOTE-037 has also reported that epacadostat combined with pembrolizumab has good antitumor effects (54).

Research on immunotherapy for small molecule receptor agonists such as immunoglobulin 2 (IgG2) CD137 agonists, and toll-like receptor 8 (TLR8) agonists are underway. Such as, IgG2 CD137 agonists combined with nivolumab for patients with advanced HNSCC (e.g., NCT02253992). TLR8 agonists stimulate the immune system, further blocking tumor cell survival. NCT01334177 was a phase Ib clinical study designed to evaluate the efficacy of the TLR8 agonist VTX-2337 combined with cetuximab in the treatment of R/M HNSCC. The results showed an objective response rate of $15 \%$ and a disease control rate of $54 \%$, with no serious toxicity or deaths; thus, the TLR8 agonist combined with cetuximab was proved to safe and effective. In NCT01836029, a phase II clinical study, patients with HNSCC also showed good tolerance to VTX-2337 combined with standard chemotherapy; however, significant differences were observed in the overall and progression-free survival (55). A further phase II clinical study of VTX-2337 in combination with nivolumab is ongoing (NCT02124850). In addition, research is being conducted on antitumor vaccines. NCT01998542, a phase II clinical trial completed in 2020, has compared the efficacy and safety of the personalized antitumor vaccine AlloVax $\left({ }^{\mathrm{TM}}\right)$ for the treatment of R/M HNSCC; the results are awaited. All of ongoing and completed immunotherapy trials are summarized in Tables $\mathbf{1}$ and 2 , respectively.

The number of immunotherapy trials for R/M HNSCC has been increasing. Different ICs act on different immune checkpoints; these are summarized in Figure 2. Great advances have been made in immunotherapy, bringing new hope for $\mathrm{R} / \mathrm{M}$ HNSCC treatment. The ongoing and completed clinical trials for different drugs and targets are summarized in Figure 3. However, the benefits of immunotherapy are limited to a small proportion of patients with HNSCC. Therefore, it is important to identify markers that respond well to immunotherapy and further screen appropriate populations for immunotherapy (56, 57). PD-L1 has been studied as a potential biomarker in CheckMate 141, KEYNOTE 040, KEYNOTE 048 (28, 30, 58). PD-L2 has also been studied as another ligand of PD-1 $(59,60)$. In addition, HPV infection may be a new target to improve the efficacy of HNSCC immunotherapy.

\section{IMMUNOTHERAPY FOR HPV- ASSOCIATED HNSCC}

In HPV-positive tumors, HPV infection leads to an increase in CRT response (61), which activates the immune response and leads to a high proportion of immune cell infiltration, thus exerting a better antitumor response (62). Conversely, HPVnegative tumors are presumed to have a relatively lower immune response. Therefore, the impact of $\mathrm{HPV}$ infection on the immunotherapeutic efficacy for HNSCC may be critical $(63,64)$.

In the KEYNOTE trials, a subset of HPV-positive patients administered pembrolizumab was evaluated to examine the relationship between HPV infection and immunotherapy. In the KEYNOTE-012, HPV-positive HNSCC patients showed a higher response rate with pembrolizumab, a higher progressionfree survival for phase Ib HPV-positive tumors (4 months vs. 2 months), and higher objective response rate (ORR) (32\% vs. $14 \%)(26,65,66)$. Similar results were also confirmed in KEYNOTE-055, although ORR and progression-free survival were similar between the two groups, overall survival in HPVpositive patients showed some advantage, even if it was not statistically significant (40). In addition, in CheckMate 141, nivolumab group showed better overall survival in HPVpositive tumors (27). A 2020 meta-analysis of 11 studies showed that HPV-positive HNSCC patients were 1.29 times more likely to respond to immunotherapy than HPV-negative HNSCC patients (risk ratio 1.29; 95\% CI $=0.85-1.96$; $\mathrm{I}^{2}=0$ ), and have a two-fold higher overall survival rate (11.5 months $v s .6 .3$ months) (29). In conclusion, the better prognosis of HPV-related HNSCC may be associated with better immunotherapy efficacy.

Given the good efficacy of immunotherapy for HPV-positive patients, a large number of immunotherapy studies targeting HPV-positive HNSCC have been conducted. Several therapeutic vaccine strategies are being studied (67). NCT00257738 is a phase I clinical trial in which patients with R/M HNSCC were administered two peptide vaccines-GL-0810 (HPV16 vaccine) and GL-0817 (MAGE-A3) - to observe their safety and immune response. The results showed that both vaccines were well tolerated and able to activate the antibody response. However, not all clinical trials have reported similar results. A phase I clinical trial using low-dose cyclophosphamide combined with the E7DNA vaccine was halted prematurely (NCT01493154).

The proportion of $\mathrm{T}$ cells in patients is closely related to the antitumor immune response (68). Therefore, antigen-specific $\mathrm{T}$ cells have become a promising immunotherapeutic strategy. An ongoing phase II clinical trial (NCT01585428II) is examining the efficacy of autologous $\mathrm{T}$ cell transfusion after genetic modification for the treatment of HPV-positive tumors (38). Meanwhile, A phase II clinical trial that observing the prognosis of patients with HPV-positive tumors treated with tumor-infiltrating lymphocyte (TIL) infusion was conducted (NCT01585428). MED10457 is a synthetic plasmid targeting the HPV E6/E7 antigen. Aggarwal et al. (69) found that $\mathrm{T}$ cells produced a large amount of $\mathrm{HPV}$-specific interferon and increased antigen-specific $\mathrm{T}$ cell infiltration with no serious adverse reactions in HPV-positive HNSCC patients administered MEDI0457 (NCT02163057). In addition, flow cytometry showed HPV-specific PD-1positive $\mathrm{T}$ cells $(0 \%$ vs. $1.8 \%)$ after using MEDI0547. The results showed that MEDI0547 can activate the tumor immune response and generate HPV-specific T cells, which has achieved some efficacy in antitumor therapy and may be used as a supplementary treatment strategy for PD-1 inhibitors. Table 3 summarizes ongoing clinical trials for HPV-positive HNSCC patients.

In conclusion, immunotherapy for HPV-positive tumors may have better effect. Next, we will further review the molecular mechanisms by which HPV-related HNSCC has a better immunotherapeutic effect. 
TABLE 1 | Summary of ongoing clinical trials in HNSCC.

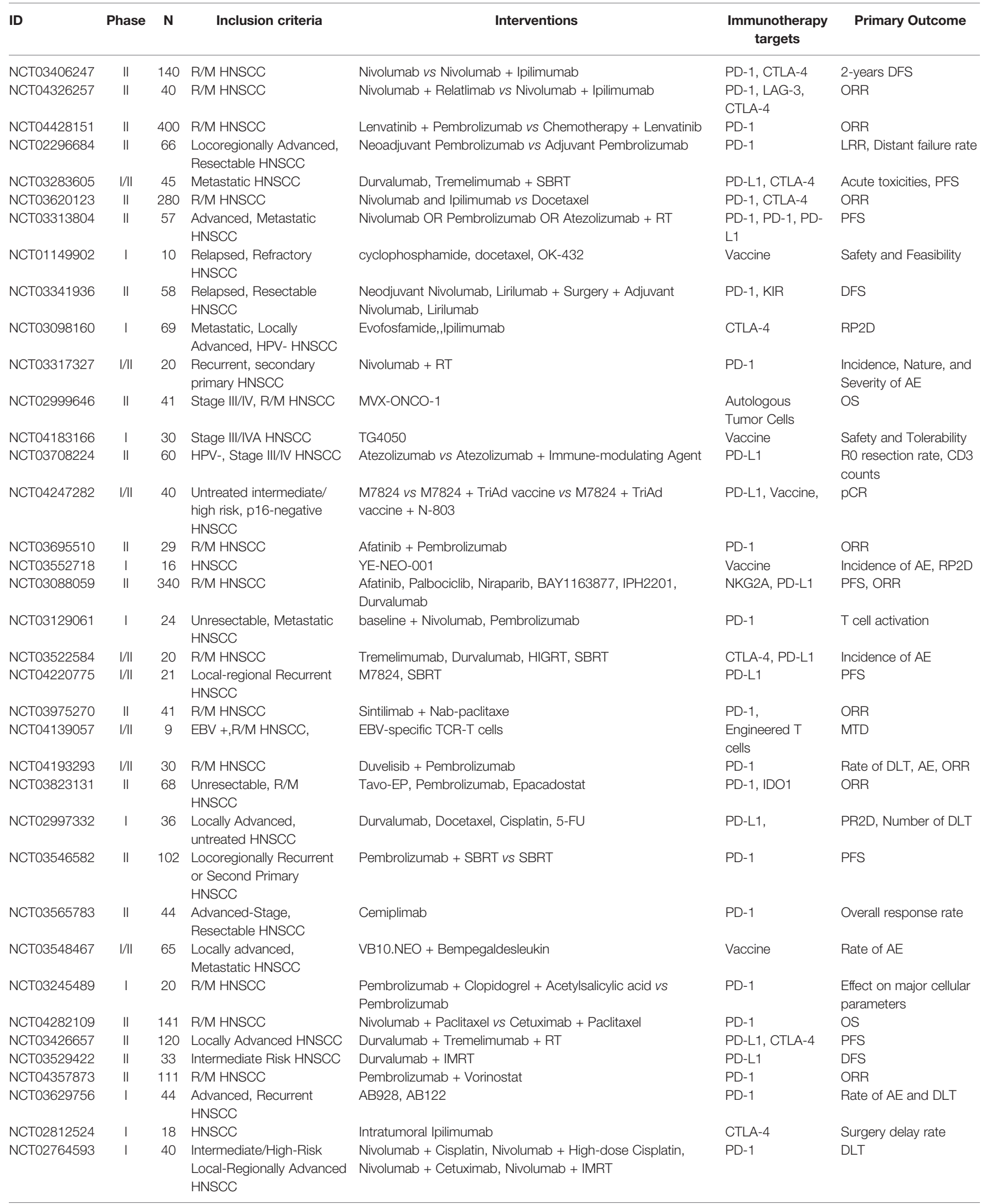


TABLE 1 | Continued

\begin{tabular}{|c|c|c|c|c|c|c|}
\hline ID & Phase & $\mathbf{N}$ & Inclusion criteria & Interventions & $\begin{array}{l}\text { Immunotherapy } \\
\text { targets }\end{array}$ & Primary Outcome \\
\hline NCT03226756 & $\|$ & 351 & R/M HNSCC & Nivolumab & PD-1 & Incidence for AEI \\
\hline NCT04107103 & $\|$ & 20 & Recurrence HNSCC & Nivolumab + Pemetrexed & PD-1 & $\begin{array}{l}\text { Feasibility, Safety/ } \\
\text { tolerability }\end{array}$ \\
\hline NCT03085719 & $\|$ & 26 & R/M HNSCC & $\begin{array}{l}\text { High Dose Radiation + Pembrolizumab vs High Dose + Low } \\
\text { Dose Radiation + Pembrolizumab }\end{array}$ & PD-1 & Overall Response Rate \\
\hline NCT03854032 & $\|$ & 48 & Stage II-IV HNSCC & BMS986205 + Nivolumab vs Nivolumab & ID01, PD-1 & ORR \\
\hline NCT02999087 & III & 688 & Locally Advanced HNSCC & $\begin{array}{l}\text { Cisplatin + IMRT vs Cetuximab + Avelumab + IMRT vs } \\
\text { Cetuximab + IMRT }\end{array}$ & PD-L1 & PFS \\
\hline NCT02274155 & 1 & 17 & Locally Advanced HNSCC & MEDI6469 & OX40 & Safety and Feasibility \\
\hline NCT04080804 & $\|$ & 60 & $\begin{array}{l}\text { Locally Advanced, } \\
\text { Resectable HNSCC }\end{array}$ & $\begin{array}{l}\text { Nivolumab + Relatlimab vs Nivolumab + Ipilimumab vs } \\
\text { Nivolumab }\end{array}$ & $\begin{array}{l}\text { PD-1, LAG-3, } \\
\text { CTLA-4 }\end{array}$ & Number of $A E$ \\
\hline NCT02955290 & $|/| \mid$ & 181 & Advanced HNSCC & CIMAvax,+ Nivolumab vs CIMAvax + Pembrolizumab & PD-1 & DLT, OS \\
\hline NCT03509012 & 1 & 360 & Advanced HNSCC & Durvalumab + Cisplatin + RT & PD-L1 & Rate of DLT and AEs \\
\hline NCT03336606 & I & 35 & $\begin{array}{l}\text { Advanced, Resectable } \\
\text { HNSCC }\end{array}$ & MEDI0562 + Surgery & OX40 & $\begin{array}{l}\text { Activation of immune } \\
\text { response }\end{array}$ \\
\hline NCT04348916 & I & 71 & $\begin{array}{l}\text { Refractory, Ineligible, } \\
\text { Relapsed HNSCC }\end{array}$ & ONCR-177 vs ONCR-177 + Pembrolizumab & Vaccine, PD-1 & Rate of DLT and AE \\
\hline NCT04129320 & $\|/ /\|$ & 750 & R/M HNSCC & $\begin{array}{l}\text { Pembrolizumab + Chemotherapy, Enoblituzumab + MGA012, } \\
\text { Enoblituzumab + MGA012 + Chemotherapy, MGA012 + } \\
\text { Chemotherapy }\end{array}$ & $\begin{array}{l}\text { PD-1, B7-H3, } \\
\text { PD-1 }\end{array}$ & $\begin{array}{l}\text { Overall Response Rate, } \\
\text { Incidence of AE, OS }\end{array}$ \\
\hline NCT02575404 & 1 & 22 & HNSCC with progression & GR-MD-02, Pembrolizumab & PD-1 & Rate of $\mathrm{AE}$ \\
\hline NCT03247712 & $\mid / I I$ & 28 & HNSCC planned for surgy & Nivolumab + RT & PD-1 & $\begin{array}{l}\text { Rate fo Delay to } \\
\text { Surgery }\end{array}$ \\
\hline NCT04007744 & I & 45 & R/M HNSCC & Sonidegib + Pembrolizumab & PD-1 & MTD, Response rate \\
\hline NCT03258554 & $\|/ I\|$ & 523 & $\begin{array}{l}\text { Locoregionally Advanced } \\
\text { HNSCC }\end{array}$ & Durvalumab + RT vs Cetuximab + RT & PD-L1 & DLT, PFS, OS \\
\hline NCT03083873 & $\|$ & 55 & R/M HNSCC & LN-145/LN-145-S1 & $\begin{array}{l}\text { Cell transfer } \\
\text { therapy }\end{array}$ & ORR \\
\hline NCT03051906 & $|/| \mid$ & 69 & Locally Advanced HNSCC & Durvalumab + Cetuximab + Radiotherapy & PD-L1 & 2-year PFS \\
\hline NCT02892201 & $\|$ & 9 & $\begin{array}{l}\text { HNSCC with Residual } \\
\text { Disease }\end{array}$ & Pembrolizumab & PD-1 & Overall response rate \\
\hline NCT03993353 & $\|$ & 30 & R/M HNSCC & Tadalafil + Pembrolizumab & PDE-5, PD-1 & Rate of DLT, OS \\
\hline NCT03665285 & $|/| \mid$ & 143 & $\begin{array}{l}\text { Advanced, metastatic } \\
\text { HNSCC }\end{array}$ & NC318 & $\begin{array}{l}\text { experimental } \\
\text { antibody }\end{array}$ & MTD, PAD \\
\hline NCT03818061 & $\|$ & 110 & R/M HNSCC & Atezolizumab + Bevacizumab & PD-L1, & Overall response rate \\
\hline NCT03228667 & $\|$ & 611 & HNSCC with progression & $\begin{array}{l}\text { ALT-803 + Pembrolizumab, Nivolumab, Atezolizumab, } \\
\text { Avelumab }\end{array}$ & PD-1, PD-L1 & ORR \\
\hline NCT03319459 & I & 100 & Advanced HNSCC & FATE-NK100 & NK cell product & Incidence of DLT \\
\hline NCT03633110 & $1 / I 1$ & 99 & HNSCC & GEN-009 Adjuvanted Vaccine + Nivolumab, Pembrolizumab & Vaccine, PD-1 & $\begin{array}{l}\text { Incidence of AE, T-cell } \\
\text { responses }\end{array}$ \\
\hline NCT02376699 & I & 135 & Advanced HNSCC & $\begin{array}{l}\text { Intravenous (IV) SEA-CD40, Pembrolizumab, Subcutaneous } \\
\text { (SC) SEA-CD40, Gemcitabine, Nab-paclitaxel }\end{array}$ & CD40, PD-1 & Incidence of $A E, O R R$ \\
\hline NCT02827838 & $\|$ & 20 & OSCC, OPSCC & Durvalumab & PD-L1 & $\begin{array}{l}\text { Immune effector, } \\
\text { Immune-regulatory miR } \\
\text { responses, }\end{array}$ \\
\hline NCT04393506 & I & 20 & $\begin{array}{l}\text { Locally Advanced and } \\
\text { Resectable OSCC }\end{array}$ & Camrelizumab, Apatinib & PD-1 & $\begin{array}{l}\text { Major pathologic } \\
\text { response }\end{array}$ \\
\hline NCT03673735 & III & 650 & HPV-negative HNSCC & Durvalumab + RT+ Cisplatin vs Placebo + RT + Cisplatin & PD-L1 & DFS \\
\hline NCT03841110 & 1 & 76 & Advanced HNSCC & FT500 & NK cell product & Rate of DLT \\
\hline
\end{tabular}

This table contains only ongoing clinical trials registered on the ClinicalTrials.gov, not including terminations or completed trials.

DFS, Disease Free Survival; R/M, Recurrence/metastasis; HNSCC, Head and neck squamous cell carcinoma; ORR, Objective Response Rate; LRR, Locoregional recurrence rates; RT, Radiation therapy; PFS, Progression-free survival; SBRT, Stereotactic Body Radiotherapy; KIR, Killer cell immunoglobulin receptor(NK cell); RP2D, Recommended phase 2 dose; OS, Overall survival; pCR, Pathologic complete response; HIGRT, Hypofractionated Image-Guided Radiation Therapy; MTD, Maximum Tolerated Dose; DLTS, dose-limiting toxicities; DLT, Dose Limiting Toxicity; AE, Adverse Events; AEI, adverse events of interest; PAD, pharmacologically active dose; OSCC, Oral Squamous Cell Carcinoma; HPV , Human papillomavirus. 
TABLE 2 | Summary of clinical trials that have been completed.

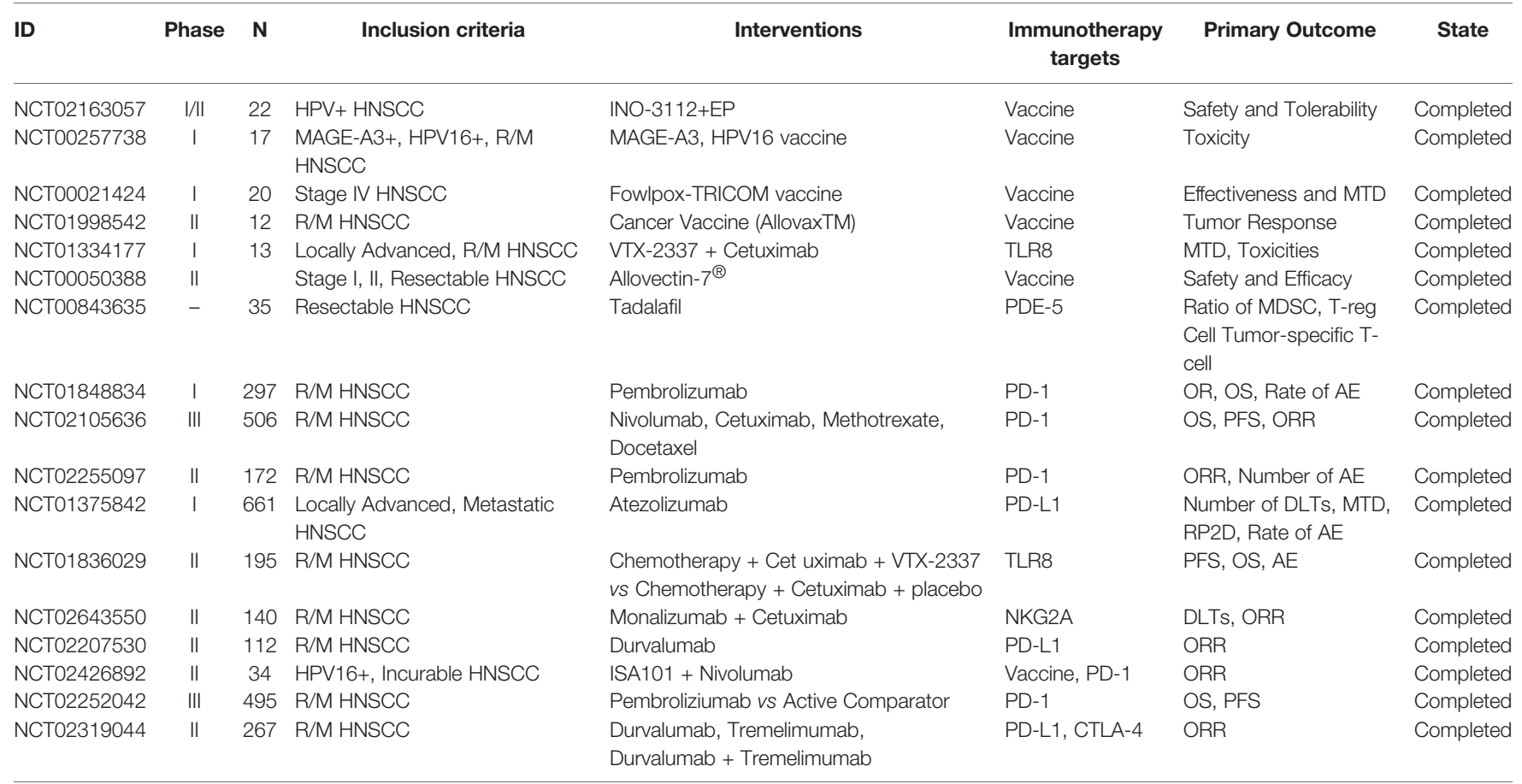

This table contains only completed clinical trials registered on the ClinicalTrials.gov.

R/M, Recurrence/metastasis; HNSCC, Head and neck squamous cell carcinoma; ORR, Objective Response Rate; PFS, Progression-free survival; RP2D, Recommended phase 2 dose; OS, Overall survival; MTD, Maximum Tolerated Dose; DLTs, Dose Limiting Toxicities; DLT, Dose Limiting Toxicity; AE, Adverse Events; HPV, Human papillomavirus; OR, Overall response.

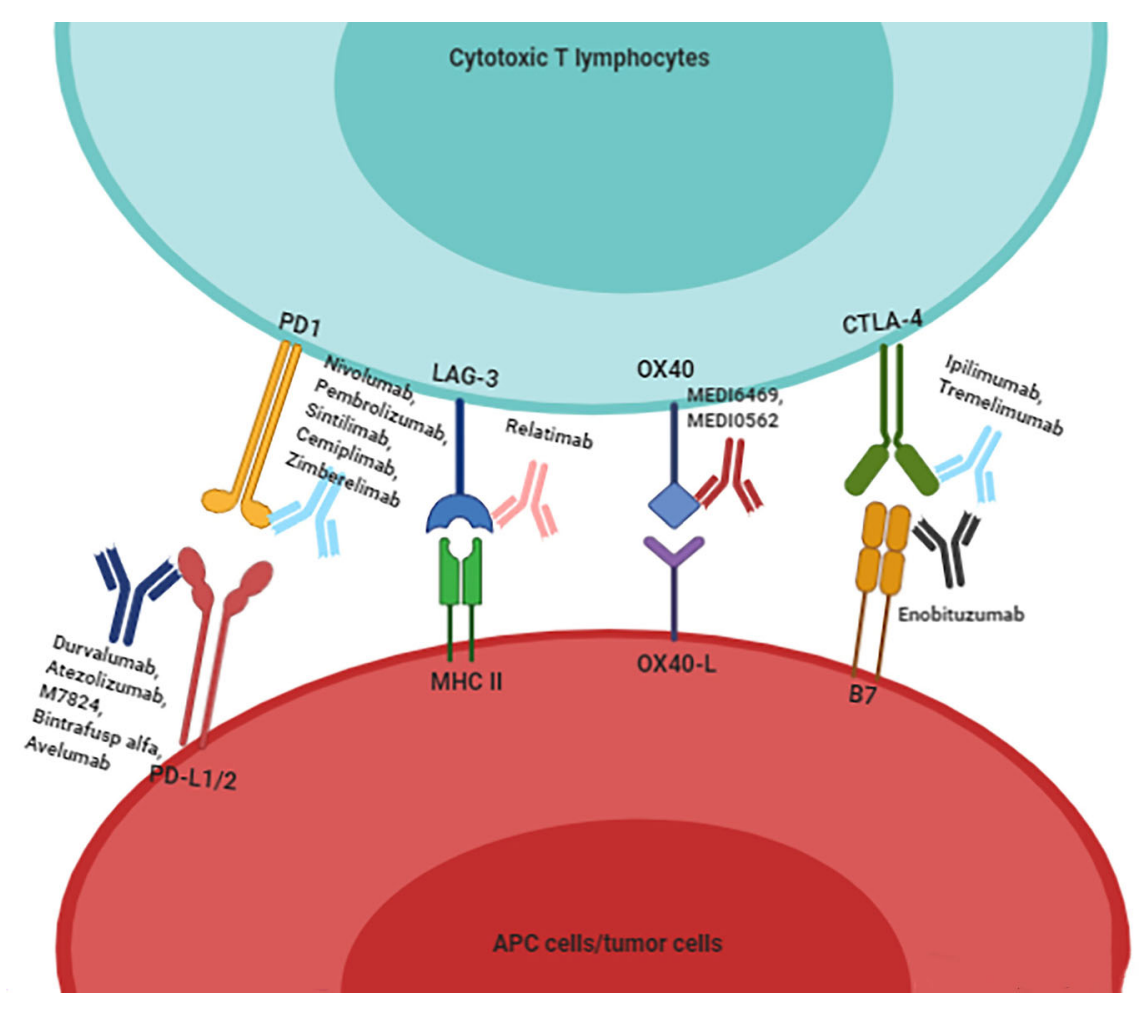

FIGURE 2 | To summarize the existing immune checkpoint inhibitors for HNSCC patients. Immunotherapy drugs combine with immune checkpoints to block the inhibitory effect of immune checkpoints on cytotoxic T lymphocytes, and then activate the proliferation and infiltration of T cells. 


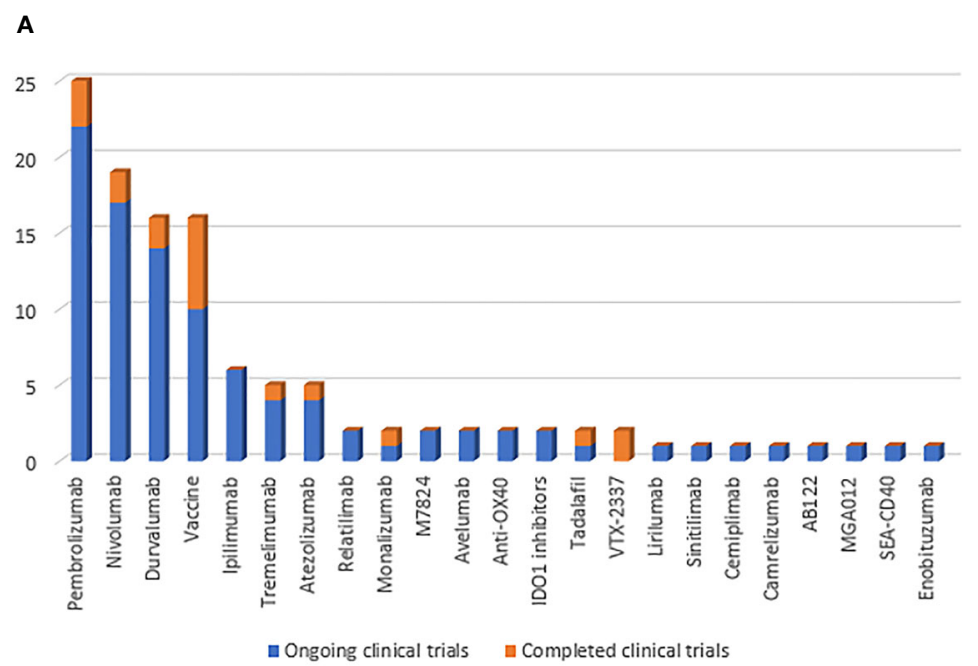

B

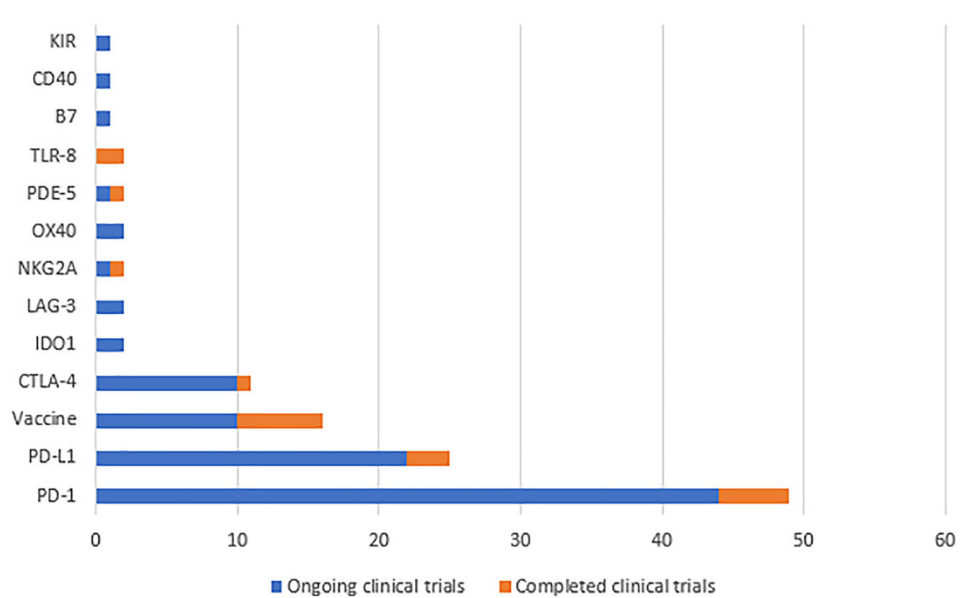

FIGURE 3 | (A) Summarize the number of clinical trials of immunotherapy drugs for HNSCC patients. (B) Summarize the number of clinical trials of immunotherapy targets for HNSCC patients. Yellow indicates completed clinical trials and blue indicates ongoing clinical trials.

\section{IMMUNE CHARACTERISTICS OF HPV- POSITIVE TUMORS}

The differences in the efficacy of immunotherapy are mainly related to the intrinsic characteristics of HPV-positive tumors, including tumor immunogenicity, immune cell infiltration, and IC expression (70).

In 2013, differences in immune cell infiltration between HPVpositive and HPV-negative HNSCC were reported for the first time; higher proportions of B cell infiltration were noted in HPV-positive tissues (71). Subsequent research by Wood et al. confirmed this finding (72). Studies have confirmed a larger proportion of CD8+T cell infiltration in HPV-positive $\operatorname{HNSCC}(31,73,74)$, which is strongly associated with improved prognosis of HPV-positive tumors $(75,76)$. TILs are often present in tumor tissues and represent an adaptive host antitumor response. Chakravarthy et al. (77) measured CD4 and CD8 mRNA abundance to compare TIL levels between HPV-positive and HPV-negative tumors, showing higher TIL levels in the HPV-positive group. Significant increases in multiple $\mathrm{T}$ cell markers were also found, indicating that lymphocyte infiltration may be a key factor leading to survival differences in HPV-positive HNSCC (77). Subsequently, in a 2014 study (78), patients were divided into high-risk and lowrisk groups based on TIL levels. The results showed a significantly higher 3-year survival rate in the high-TIL group than in the lowTIL group. Similar results were reported in two studies by King and Nasman $(79,80)$. Therefore, a high proportion of TILs may play an antitumor role through adaptive host immune response, which may contribute to increased survival of HPV-positive patients $(81,82)$. Treg cells are a subset of $\mathrm{T}$ cells with immunosuppressive effects, 
TABLE 3 | Ongoing clinical trials for HPV-positive HNSCC.

\begin{tabular}{|c|c|c|c|c|c|c|}
\hline ID & Phase & $\mathbf{N}$ & Inclusion criteria & Interventions & $\begin{array}{l}\text { Immunotherapy } \\
\text { targets }\end{array}$ & Main outcome \\
\hline NCT03383094 & $\|$ & 114 & $\begin{array}{l}\text { Advanced/Intermediate-Risk p16 } \\
+ \text { HNSCC }\end{array}$ & Pembrolizumab + RT vs Cisplatin + RT & PD-1 & PFS \\
\hline NCT03578406 & 1 & 20 & HPV+R/M HNSCC & HPV E6-specific TCR-T cells & Engineered T cells & MTD \\
\hline NCT02002182 & $\|$ & 15 & $\mathrm{HPV}+\mathrm{HNSCC}$ & ADXS 11-001 vs Control & Vaccine & $\begin{array}{l}\text { HPV-Specific T Cell Response } \\
\text { Rate }\end{array}$ \\
\hline NCT03618134 & $|/| \mid$ & 82 & $\mathrm{HPV}+\mathrm{OPSCC}$ & $\begin{array}{l}\text { SBRT + Durvalumab + surgery vs } \\
\text { SBRT + Durvalumab + Tremelimumab + } \\
\text { surgery }\end{array}$ & PD-L1, CTLA-4 & Incidence of adverse events, PFS \\
\hline NCT04260126 & $\|$ & 96 & HPV16+R/M HNSCC & Pembrolizumab+PDS0101 & $\begin{array}{l}\text { PD-1, } \\
\text { T-cell immunotherapy }\end{array}$ & ORR \\
\hline NCT03162224 & $|/| \mid$ & 35 & $\mathrm{HPV}+\mathrm{R} / \mathrm{M}$ HNSCC & MEDI0457, Durvalumab & $\begin{array}{l}\text { Vaccine, } \\
\text { PD-L1 }\end{array}$ & $\begin{array}{l}\text { Number of patients with changes } \\
\text { in ECG, Occurrence of SAEs }\end{array}$ \\
\hline
\end{tabular}

This table contains only clinical trials registered on the ClinicalTrials, gov for HPV-positive HNSCC that are in progressing and do not include terminated or completed.

RT, Radiation therapy; HNSCC, Head and neck squamous cell carcinoma; PFS, Progression-free survival; R/M, Recurrence/metastasis; MTD, The Maximum Tolerated Dose; OPSCC, Oropharyngeal squamous cell carcinoma; SBRT, Stereotactic Body Radiotherapy; ORR, Objective Response Rate; ECG, Electrocariogram; SAEs, Serious adverse events; HPV, Human papillomavirus.

which inhibit the immune responses of other cells through Foxp3, CD25, and other transfer factors. Treg cells are usually associated with poor prognosis. However, recent findings in HPV-positive HNSCC show the opposite (72). NK cells are an important part of innate immunity. In HPV-positive tumors, NK cells also have higher levels of infiltration (83) and are associated with better prognosis $(31,72)$. Therefore, in HPV-positive tumor tissues, the high proportions of TILs infiltration, CD8+ T cells, Treg cells, NK cells, and other immune cells may explain the better prognosis (84-86).

In addition, in an analysis of TCGA Database, Marij et al. (87) found that HPV-specific T cells are present in HPV-positive tumors and that their presence is associated with better survival. Studies have also confirmed the presence of HPV-specific T lymphocytes in the peripheral blood of HPV-positive HNSCC patients in vitro (88). A recent study compared the immune spectra of HPV-positive and HPV-negative tumors by single-cell RNA and multispectral immunofluorescence analysis, reporting the presence of germinal center B cells in HPV-positive TILs and low percentages of B cells in HPV-negative HNSCC, with most in a non-germinal center state (89). Therefore, differences in immune cell infiltration may be one of the reasons for the good prognosis in HPV-positive HNSCC.

Through gene expression analysis, Wood et al. confirmed increased expressions of PD1, CTLA-4, and T-cell immunoglobulin and mucin-domain containing-3 (TIM-3) in HPV-positive HNSCC $(72,90)$. With the discovery of PD-L1 in head and neck tissue, higher PD-L1 expression and activity have been found in HPV-driven $\operatorname{HNSCC}(91,92)$, which was associated with a good prognosis (93). PD1+ TILs were present in HPV-positive HNSCC, suggesting that PD-1 may play an important role in HPV-positive HNSCC (91). Some studies also speculated that TILs promote PD-L1 expression in HPV-positive HNSCC tumor cells through the secretion of pheromone $-\gamma(81)$ to explain the expression levels exceeding $70 \%(91,94)$. The higher expression level of CTLA-4 may be related to the higher proportion of $\mathrm{T}$ cells expressing CTLA-4 (31). During HPV infection, high levels and activity of PD-1, PD-L1, and CTLA-4 may contribute to the good effects of ICs in HPV-positive HNSCC patients.

\section{CONCLUSION}

After surgery, radiotherapy, chemotherapy, and targeted therapy, the emergence of immunotherapy has ushered in a new era in the treatment of HNSCC. Inhibitors based on immune checkpoints such as PD-1, PD-L1 have achieved good clinical efficacy, and clinical studies on multitarget combined immunotherapy, immunotherapy combined with traditional radiotherapy, chemotherapy, and IC combined with small molecular agonists are also being performed. The development of immunotherapy brings hope of new treatment options and survival for advanced HNSCC patients. However, their efficiency is only about $20 \%$. Therefore, patient selection and the discovery of effective biomarkers for immunotherapy are important.

HPV infection is a newly discovered risk factor of HNSCC. Patients with HPV-positive tumors have better prognosis than HPV-negative tumors, which may be related to better treatment outcomes. Subgroup analysis of the KEYNOTE-012, 055 trials showed better responses in HPV-positive patients using pembrolizumab. Subsequently, trials on immunotherapy for HPV-positive HNSCC patients were gradually performed, including those for a immunomodulatory vaccine for HPVE6/E7 and auto-specific T-cell transfusion. HPV-positive patients have become a special group for immunotherapy. However, some studies have suggested that there is no significant advantage in immunotherapy for patients with HPV-positive HNSCC (95). So further research is needed to determine if immunotherapy can achieve better clinical benefits in these patients.

Studies have confirmed higher immune cell infiltration and expression levels of PD-1, PD-L1, and other immune checkpoints in HPV-positive tumors, which may be the key factor for better efficacy of immunotherapy. Further research on the immune system and immune microenvironment of HPV-positive tumors will provide a new theoretical basis for individual immunotherapy of HPV- 
positive patients and lay a foundation for screening suitable populations for immunotherapy. In addition, further in vitro and in vivo studies of HPV-positive tumors related to the immune system and further exploration of potential immune-related targets in HPVpositive cells are essential to improve the immunotherapeutic efficacy of immune-tolerant HNSCC.

\section{AUTHOR CONTRIBUTIONS}

Conceptualization, XJ and YX. Software, investigation, HW, QZhang, YYZ, ZZ, and ZL. Resources, YX. Writing-original draft preparation, HW, QZhao, SL, ZL, and XJ. Writing-review and editing, LM, YX, and XJ. Funding acquisition, XJ. All authors contributed to the article and approved the submitted version.

\section{REFERENCES}

1. Who Globocan 2018 Database. World Health Organization (Who). Available at: http://gco.iarc.fr/today (Accessed on 30 January 2021).

2. LeHew CW, Weatherspoon DJ, Peterson CE, Goben A, Reitmajer K, Sroussi H, et al. The Health System and Policy Implications of Changing Epidemiology for Oral Cavity and Oropharyngeal Cancers in the United States From 1995 to 2016. Epidemiol Rev (2017) 39(1):132-47. doi: 10.1093/epirev/mxw001

3. Weatherspoon DJ, Chattopadhyay A, Boroumand S, Garcia I. Oral Cavity and Oropharyngeal Cancer Incidence Trends and Disparities in the United States: 20002010. Cancer Epidemiol (2015) 39(4):497-504. doi: 10.1016/j.canep.2015.04.007

4. Castellsagué X, Alemany L, Quer M, Halec G, Quirós B, Tous S, et al. Hpv Involvement in Head and Neck Cancers: Comprehensive Assessment of Biomarkers in 3680 Patients. J Natl Cancer Inst (2016) 108(6):djv403. doi: $10.1093 /$ jnci/djv403

5. Jordan RC, Lingen MW, Perez-Ordonez B, He X, Pickard R, Koluder M, et al. Validation of Methods for Oropharyngeal Cancer HPV Status Determination in US Cooperative Group Trials. Am J Surg Pathol (2012) 36(7):945-54. doi: 10.1097/PAS.0b013e318253a2d1

6. Bravo IG, Félez-Sánchez M. Papillomaviruses: Viral Evolution, Cancer and Evolutionary Medicine. Evol Med Public Health (2015) 2015(1):32-51. doi: 10.1093/emph/eov003

7. Kreimer AR, Ferreiro-Iglesias A, Nygard M, Bender N, Schroeder L, Hildesheim A, et al. Timing of HPV16-E6 Antibody Seroconversion Before OPSCC: Findings From the HPVC3 Consortium. Ann Oncol (2019) 30 (8):1335-43. doi: 10.1093/annonc/mdz138

8. Kreimer AR, Clifford GM, Boyle P, Franceschi S. Human Papillomavirus Types in Head and Neck Squamous Cell Carcinomas Worldwide: A Systematic Review. Cancer Epidemiol Biomarkers Prev (2005) 14(2):467-75. doi: 10.1158/1055-9965.EPI-04-0551

9. Pinatti LM, Walline HM, Carey TE. Human Papillomavirus Genome Integration and Head and Neck Cancer. J Dent Res (2018) 97(6):691-700. doi: $10.1177 / 0022034517744213$

10. Puram SV, Rocco JW. Molecular Aspects of Head and Neck Cancer Therapy. Hematol Oncol Clin North Am (2015) 29(6):971-92. doi: 10.1016/j.hoc.2015.07.003

11. Luo X, Donnelly CR, Gong W, Heath BR, Hao Y, Donnelly LA, et al. HPV16 Drives Cancer Immune Escape Via NLRX1-mediated Degradation of STING. J Clin Invest (2020) 130(4):1635-52. doi: 10.1172/JCI129497

12. Kanodia S, Fahey LM, Kast WM. Mechanisms Used by Human Papillomaviruses to Escape the Host Immune Response. Curr Cancer Drug Targets (2007) 7(1):79-89. doi: 10.2174/156800907780006869

13. Fakhry C, Zhang Q, Nguyen-Tan PF, Rosenthal D, El-Naggar A, Garden AS, et al. Human Papillomavirus and Overall Survival After Progression of Oropharyngeal Squamous Cell Carcinoma. J Clin Oncol (2014) 32 (30):3365-73. doi: 10.1200/JCO.2014.55.1937

14. Ang KK, Harris J, Wheeler R, Weber R, Rosenthal DI, Nguyen-Tan PF, et al. Human Papillomavirus and Survival of Patients With Oropharyngeal Cancer. N Engl J Med (2010) 363(1):24-35. doi: 10.1056/NEJMoa0912217

\section{FUNDING}

This research was funded in part by grants from the National Natural Science Foundation of China (81570344, to YX), the Norman Bethune Program of Jilin University (2015225, to YX and 2015203, to XJ), National Key R\&D Program of China (2017YFC0112100, to XJ), and the Jilin Provincial Science and Technology Foundations $(20180414039 \mathrm{GH}$ to YX and 20190201200JC to XJ).

\section{ACKNOWLEDGMENTS}

We would like to thank Editage (www.editage.cn) for English language editing.

15. Wang H, Wei J, Wang B, Meng L, Xin Y, Dong L, et al. Role of Human Papillomavirus in Laryngeal Squamous Cell Carcinoma: A Meta-Analysis of Cohort Study. Cancer Med (2020) 9(1):204-14. doi: 10.1002/cam4.2712

16. Wang H, Wang B, Wei J, Meng L, Zhang Q, Qu C, et al. Molecular Mechanisms Underlying Increased Radiosensitivity in Human Papillomavirus-Associated Oropharyngeal Squamous Cell Carcinoma. Int J Biol Sci (2020) 16(6):1035-43. doi: 10.7150/ijbs.40880

17. Chang JH, Wu CC, Yuan KS, Wu ATH, Wu SY. Locoregionally Recurrent Head and Neck Squamous Cell Carcinoma: Incidence, Survival, Prognostic Factors, and Treatment Outcomes. Oncotarget (2017) 8(33):55600-12. doi: 10.18632/oncotarget. 16340

18. Bourhis J, Overgaard J, Audry H, Ang KK, Saunders M, Bernier J, et al. Hyperfractionated or Accelerated Radiotherapy in Head and Neck Cancer: A Meta-Analysis. Lancet (2006) 368(9538):843-54. doi: 10.1016/S0140-6736(06) 69121-6

19. Pignon JP, le Maître A, Maillard E, Bourhis J. Meta-Analysis of Chemotherapy in Head and Neck Cancer (MACH-NC): An Update on 93 Randomised Trials and 17,346 Patients. Radiother Oncol (2009) 92(1):4-14. doi: 10.1016/ j.radonc.2009.04.014

20. Argiris A, Karamouzis MV, Raben D, Ferris RL. Head and Neck Cancer. Lancet (2008) 371(9625):1695-709. doi: 10.1016/S0140-6736(08)60728-X

21. Seiwert TY, Cohen EE. State-of-the-Art Management of Locally Advanced Head and Neck Cancer. Br J Cancer (2005) 92(8):1341-8. doi: 10.1038/sj.bjc.6602510

22. Jayaram SC, Muzaffar SJ, Ahmed I, Dhanda J, Paleri V, Mehanna H. Efficacy, Outcomes, and Complication Rates of Different Surgical and Nonsurgical Treatment Modalities for Recurrent/Residual Oropharyngeal Carcinoma: A Systematic Review and Meta-Analysis. Head Neck (2016) 38(12):1855-61. doi: 10.1002/hed.24531

23. Andrews LP, Yano H, Vignali DAA. Inhibitory Receptors and Ligands Beyond PD-1, Pd-L1 and CTLA-4: Breakthroughs or Backups. Nat Immunol (2019) 20(11):1425-34. doi: 10.1038/s41590-019-0512-0

24. Heineman TE, Widman A, Kuan EC, St John M. The Genetic Landscape of Programmed Death Ligand-1 (PD-L1) Alterations in Head and Neck Cancer. Laryngoscope Investig Otolaryngol (2017) 2(3):99-103. doi: 10.1002/lio2.79

25. Matoba T, Imai M, Ohkura N, Kawakita D, Ijichi K, Toyama T, et al. Regulatory T Cells Expressing Abundant CTLA-4 on the Cell Surface With a Proliferative Gene Profile are Key Features of Human Head and Neck Cancer. Int J Cancer (2019) 144(11):2811-22. doi: 10.1002/ijc.32024

26. Seiwert TY, Burtness B, Mehra R, Weiss J, Berger R, Eder JP, et al. Safety and Clinical Activity of Pembrolizumab for Treatment of Recurrent or Metastatic Squamous Cell Carcinoma of the Head and Neck (KEYNOTE-012): An Open-Label, Multicentre, Phase 1b Trial. Lancet Oncol (2016) 17(7):956-65. doi: 10.1016/S1470-2045(16)30066-3

27. Ferris RL, Blumenschein G Jr, Fayette J, Guigay J, Colevas AD, Licitra L, et al. Nivolumab for Recurrent Squamous-Cell Carcinoma of the Head and Neck. N Engl J Med (2016) 375(19):1856-67. doi: 10.1056/NEJMoa1602252

28. Burtness B, Harrington KJ, Greil R, Soulières D, Tahara M, de Castro G Jr, et al. Pembrolizumab Alone or With Chemotherapy Versus Cetuximab With 
Chemotherapy for Recurrent or Metastatic Squamous Cell Carcinoma of the Head and Neck (KEYNOTE-048): A Randomised, Open-Label, Phase 3 Study. Lancet (2019) 394(10212):1915-28. doi: 10.1016/s0140-6736(19)32591-7

29. Galvis MM, Borges G, Oliveira T, Toledo I, Castilho R, Guerra E, et al. Immunotherapy Improves Efficacy and Safety of Patients With HPV Positive and Negative Head and Neck Cancer: A Systematic Review and Meta-Analysis. Crit Rev Oncol Hematol (2020) 150:102966. doi: 10.1016/j.critrevonc.2020.102966

30. Cohen EEW, Soulières D, Le Tourneau C, Dinis J, Licitra L, Ahn MJ, et al. Pembrolizumab Versus Methotrexate, Docetaxel, or Cetuximab for Recurrent or Metastatic Head-and-Neck Squamous Cell Carcinoma (KEYNOTE-040): A Randomised, Open-Label, Phase 3 Study. Lancet (2019) 393(10167):156-67. doi: 10.1016/s0140-6736(18)31999-8

31. Mandal R, Senbabaoğlu Y, Desrichard A, Havel JJ, Dalin MG, Riaz N, et al. The Head and Neck Cancer Immune Landscape and its Immunotherapeutic Implications. JCI Insight (2016) 1(17):e89829. doi: 10.1172/jci.insight.89829

32. Wang Y, Xu Y, Hua Q, Jiang Y, Liu P, Zhang W, et al. Novel Prognostic Model Based on Immune Signature for Head and Neck Squamous Cell Carcinoma. BioMed Res Int (2020) 2020:4725314. doi: 10.1155/2020/4725314

33. Zhang F, Liu Y, Yang Y, Yang K. Development and Validation of a FourteenInnate Immunity-Related Gene Pairs Signature for Predicting Prognosis Head and Neck Squamous Cell Carcinoma. BMC Cancer (2020) 20(1):1015. doi: 10.1186/s12885-020-07489-7

34. Varilla V, Atienza J, Dasanu CA. Immune Alterations and Immunotherapy Prospects in Head and Neck Cancer. Expert Opin Biol Ther (2013) 13 (9):1241-56. doi: 10.1517/14712598.2013.810716

35. Economopoulou P, Perisanidis C, Giotakis EI, Psyrri A. The Emerging Role of Immunotherapy in Head and Neck Squamous Cell Carcinoma (HNSCC): Anti-Tumor Immunity and Clinical Applications. Ann Transl Med (2016) 4 (9):173. doi: 10.21037/atm.2016.03.34

36. Puntigam LK, Jeske SS, Götz M, Greiner J, Laban S, Theodoraki MN, et al. Immune Checkpoint Expression on Immune Cells of HNSCC Patients and Modulation by Chemo- and Immunotherapy. Int J Mol Sci (2020) 21 (15):5181. doi: 10.3390/ijms21155181

37. Green SE, McCusker MG, Mehra R. Emerging Immune Checkpoint Inhibitors for the Treatment of Head and Neck Cancers. Expert Opin Emerg Drugs (2020) 25(4):501-14. doi: 10.1080/14728214.2020.1852215

38. Ferris RL. Immunology and Immunotherapy of Head and Neck Cancer. J Clin Oncol (2015) 33(29):3293-304. doi: 10.1200/JCO.2015.61.1509

39. Sunshine J, Taube JM. Pd-1/Pd-L1 Inhibitors. Curr Opin Pharmacol (2015) 23:32-8. doi: 10.1016/j.coph.2015.05.011

40. Bauml J, Seiwert TY, Pfister DG, Worden F, Liu SV, Gilbert J, et al. Pembrolizumab for Platinum- and Cetuximab-Refractory Head and Neck Cancer: Results From a Single-Arm, Phase II Study. J Clin Oncol (2017) 35 (14):1542-9. doi: 10.1200/JCO.2016.70.1524

41. Gulley JL, Repasky EA, Wood LS, Butterfield LH. Highlights of the 31st Annual Meeting of the Society for Immunotherapy of Cancer (Sitc), 2016. J Immunother Cancer (2017) 5(1):55. doi: 10.1186/s40425-017-0262-1

42. Adusumilli PS, Cha E, Cornfeld M, Davis T, Diab A, Dubensky TW Jr, et al. New Cancer Immunotherapy Agents in Development: A Report From an Associated Program of the 31(St)Annual Meeting of the Society for Immunotherapy of Cancer, 2016. J Immunother Cancer (2017) 5:50. doi: 10.1186/s40425-017-0253-2

43. Massarelli E, William W, Johnson F, Kies M, Ferrarotto R, Guo M, et al. Combining Immune Checkpoint Blockade and Tumor-Specific Vaccine for Patients With Incurable Human Papillomavirus 16-Related Cancer: A Phase 2 Clinical Trial. JAMA Oncol (2019) 5(1):67-73. doi: 10.1001/jamaoncol.2018.4051

44. Zandberg DP, Algazi AP, Jimeno A, Good JS, Fayette J, Bouganim N, et al. Durvalumab for Recurrent or Metastatic Head and Neck Squamous Cell Carcinoma: Results From a Single-Arm, Phase II Study in Patients With $\geq 25 \%$ Tumour Cell PD-L1 Expression Who Have Progressed on Platinum-Based Chemotherapy. Eur J Cancer (2019) 107:142-52. doi: 10.1016/j.ejca.2018.11.015

45. Colevas AD, Bahleda R, Braiteh F, Balmanoukian A, Brana I, Chau NG, et al. Safety and Clinical Activity of Atezolizumab in Head and Neck Cancer: Results From a Phase I Trial. Ann Oncol (2018) 29(11):2247-53. doi: 10.1093/annonc/mdy411

46. Siu LL, Even C, Mesía R, Remenar E, Daste A, Delord JP, et al. Safety and Efficacy of Durvalumab With or Without Tremelimumab in Patients With PD-L1-Low/Negative Recurrent or Metastatic Hnscc: The Phase 2 CONDOR Randomized Clinical Trial. JAMA Oncol (2019) 5(2):195-203. doi: 10.1001/ jamaoncol.2018.4628
47. Ferris RL, Haddad R, Even C, Tahara M, Dvorkin M, Ciuleanu TE, et al. Durvalumab With or Without Tremelimumab in Patients With Recurrent or Metastatic Head and Neck Squamous Cell Carcinoma: EAGLE, a Randomized, Open-Label Phase III Study. Ann Oncol (2020) 31(7):942-50. doi: 10.1016/j.annonc.2020.04.001

48. Prendergast GC, Malachowski WJ, Mondal A, Scherle P, Muller AJ. Indoleamine 2,3-Dioxygenase and Its Therapeutic Inhibition in Cancer. Int Rev Cell Mol Biol (2018) 336:175-203. doi: 10.1016/bs.ircmb.2017.07.004

49. Adams S, Braidy N, Bessede A, Brew BJ, Grant R, Teo C, et al. The Kynurenine Pathway in Brain Tumor Pathogenesis. Cancer Res (2012) 72(22):5649-57. doi: 10.1158/0008-5472.CAN-12-0549

50. Maliniemi P, Laukkanen K, Väkevä L, Dettmer K, Lipsanen T, Jeskanen L, et al. Biological and Clinical Significance of Tryptophan-Catabolizing Enzymes in Cutaneous T-cell Lymphomas. Oncoimmunology (2017) 6(3): e1273310. doi: 10.1080/2162402X.2016.1273310

51. Godin-Ethier J, Hanafi LA, Piccirillo CA, Lapointe R. Indoleamine 2,3Dioxygenase Expression in Human Cancers: Clinical and Immunologic Perspectives. Clin Cancer Res (2011) 17(22):6985-91. doi: 10.1158/10780432.CCR-11-1331

52. Prendergast GC, Malachowski WP, DuHadaway JB, Muller AJ. Discovery of IDO1 Inhibitors: From Bench to Bedside. Cancer Res (2017) 77(24):6795-811. doi: 10.1158/0008-5472.CAN-17-2285

53. Nayak-Kapoor A, Hao Z, Sadek R, Dobbins R, Marshall L, Vahanian NN, et al. Phase Ia Study of the Indoleamine 2,3-Dioxygenase 1 (IDO1) Inhibitor Navoximod (GDC-0919) in Patients With Recurrent Advanced Solid Tumors. J Immunother Cancer (2018) 6(1):61. doi: 10.1186/s40425-018-0351-9

54. Mitchell TC, Hamid O, Smith DC, Bauer TM, Wasser JS, Olszanski AJ, et al. Epacadostat Plus Pembrolizumab in Patients With Advanced Solid Tumors: Phase I Results From a Multicenter, Open-Label Phase I/Ii Trial (Echo-202/ Keynote-037). J Clin Oncol (2018) 36(32):3223-30. doi: 10.1200/ JCO.2018.78.9602

55. Ferris RL, Saba NF, Gitlitz BJ, Haddad R, Sukari A, Neupane P, et al. Effect of Adding Motolimod to Standard Combination Chemotherapy and Cetuximab Treatment of Patients With Squamous Cell Carcinoma of the Head and Neck: The Active8 Randomized Clinical Trial. JAMA Oncol (2018) 4(11):1583-8. doi: $10.1001 /$ jamaoncol.2018.1888

56. Wolchok JD, Chiarion-Sileni V, Gonzalez R, Rutkowski P, Grob JJ, Cowey $\mathrm{CL}$, et al. Overall Survival With Combined Nivolumab and Ipilimumab in Advanced Melanoma. N Engl J Med (2017) 377(14):1345-56. doi: 10.1056/ NEJMoa1709684

57. Bonomi M, Bhateja P, Issa M, Klamer B, Pan X, Blakaj A, et al. A Predictive Survival Model for Patients With Head and Neck Squamous Cell Carcinoma Treated With Immune Check Point Inhibitors. Oral Oncol (2020) 110:104900. doi: 10.1016/j.oraloncology.2020.104900

58. Ferris RL, Blumenschein G Jr, Fayette J, Guigay J, Colevas AD, Licitra L, et al. Nivolumab vs Investigator's Choice in Recurrent or Metastatic Squamous Cell Carcinoma of the Head and Neck: 2-Year Long-Term Survival Update of CheckMate 141 With Analyses by Tumor PD-L1 Expression. Oral Oncol (2018) 81:45-51. doi: 10.1016/j.oraloncology.2018.04.008

59. Outh-Gauer S, Alt M, Le Tourneau C, Augustin J, Broudin C, Gasne C, et al. Immunotherapy in Head and Neck Cancers: A New Challenge for Immunologists, Pathologists and Clinicians. Cancer Treat Rev (2018) 65:5464. doi: 10.1016/j.ctrv.2018.02.008

60. Yearley J, Gibson C, Yu N, Moon C, Murphy E, Juco J, et al. Pd-L2 Expression in Human Tumors: Relevance to Anti-PD-1 Therapy in Cancer. Clin Cancer Res (2017) 23: (12):3158-67. doi: 10.1158/1078-0432.CCR-16-1761

61. Spanos WC, Nowicki P, Lee DW, Hoover A, Hostager B, Gupta A, et al. Immune Response During Therapy With Cisplatin or Radiation for Human Papillomavirus-Related Head and Neck Cancer. Arch Otolaryngol Head Neck Surg (2009) 135(11):1137-46. doi: 10.1001/archoto.2009.159

62. Stanley M. HPV - Immune Response to Infection and Vaccination. Infect Agent Cancer (2010) 5:19. doi: 10.1186/1750-9378-5-19

63. Whiteside TL. Immune Responses to Cancer: Are They Potential Biomarkers of Prognosis? Front Oncol (2013) 3:107. doi: 10.3389/fonc.2013.00107

64. Nguyen N, Bellile E, Thomas D, McHugh J, Rozek L, Virani S, et al. Tumor Infiltrating Lymphocytes and Survival in Patients With Head and Neck Squamous Cell Carcinoma. Head Neck (2016) 38(7):1074-84. doi: 10.1002/ hed.24406 
65. Mehra R, Seiwert TY, Gupta S, Weiss J, Gluck I, Eder JP, et al. Efficacy and Safety of Pembrolizumab in Recurrent/Metastatic Head and Neck Squamous Cell Carcinoma: Pooled Analyses After Long-Term Follow-Up in KEYNOTE012. Br J Cancer (2018) 119(2):153-9. doi: 10.1038/s41416-018-0131-9

66. Chow LQM, Haddad R, Gupta S, Mahipal A, Mehra R, Tahara M, et al. Antitumor Activity of Pembrolizumab in Biomarker-Unselected Patients With Recurrent and/or Metastatic Head and Neck Squamous Cell Carcinoma: Results From the Phase Ib KEYNOTE-012 Expansion Cohort. J Clin Oncol (2016) 34(32):3838-45. doi: 10.1200/jco.2016.68.1478

67. Sewell DA, Pan ZK, Paterson Y. Listeria-Based HPV-16 E7 Vaccines Limit Autochthonous Tumor Growth in a Transgenic Mouse Model for HPV-16 Transformed Tumors. Vaccine (2008) 26(41):5315-20. doi: 10.1016/ j.vaccine.2008.07.036

68. June $\mathrm{CH}$. Adoptive $\mathrm{T}$ Cell Therapy for Cancer in the Clinic. J Clin Invest (2007) 117(6):1466-76. doi: 10.1172/JCI32446

69. Aggarwal C, Cohen RB, Morrow MP, Kraynyak KA, Sylvester AJ, Knoblock DM, et al. Immunotherapy Targeting Hpvl6/18 Generates Potent Immune Responses in HPV-Associated Head and Neck Cancer. Clin Cancer Res (2019) 25(1):110-24. doi: 10.1158/1078-0432.CCR-18-1763

70. Kanaan H, Kourie HR, Awada AH. Are Virus-Induced Cancers More Sensitive to Checkpoint Inhibitors? Future Oncol (2016) 12(23):2665-8. doi: 10.2217/fon-2016-0283

71. Russell S, Angell T, Lechner M, Liebertz D, Correa A, Sinha U, et al. Immune Cell Infiltration Patterns and Survival in Head and Neck Squamous Cell Carcinoma. Head Neck Oncol (2013) 5(3):24.

72. Wood O, Woo J, Seumois G, Savelyeva N, McCann KJ, Singh D, et al. Gene Expression Analysis of TIL Rich HPV-Driven Head and Neck Tumors Reveals a Distinct B-Cell Signature When Compared to HPV Independent Tumors. Oncotarget (2016) 7(35):56781-97. doi: 10.18632/oncotarget.10788

73. Näsman A, Romanitan M, Nordfors C, Grün N, Johansson H, Hammarstedt L, et al. Tumor Infiltrating CD8+ and Foxp3+ Lymphocytes Correlate to Clinical Outcome and Human Papillomavirus (HPV) Status in Tonsillar Cancer. PLoS One (2012) 7(6):e38711. doi: 10.1371/journal.pone.0038711

74. Green VL, Michno A, Stafford ND, Greenman J. Increased Prevalence of Tumour Infiltrating Immune Cells in Oropharyngeal Tumours in Comparison to Other Subsites: Relationship to Peripheral Immunity. Cancer Immunol Immunother (2013) 62(5):863-73. doi: 10.1007/s00262-013-1395-9

75. Yin W, Duluc D, Joo H, Oh S. Dendritic Cell Targeting Vaccine for HPVassociated Cancer. Cancer Cell Microenviron (2016) 3(4):e1482.

76. Matlung SE, Wilhelmina van Kempen PM, Bovenschen N, van Baarle D, Willems SM. Differences in T-Cell Infiltrates and Survival Between HPV+ and HPV- Oropharyngeal Squamous Cell Carcinoma. Future Sci OA (2016) 2(1): Fso88. doi: $10.4155 /$ fso. 15.88

77. Chakravarthy A, Henderson S, Thirdborough SM, Ottensmeier CH, Su X, Lechner M, et al. Human Papillomavirus Drives Tumor Development Throughout the Head and Neck: Improved Prognosis Is Associated With an Immune Response Largely Restricted to the Oropharynx. J Clin Oncol (2016) 34(34):4132-41. doi: 10.1200/JCO.2016.68.2955

78. Ward MJ, Thirdborough SM, Mellows T, Riley C, Harris S, Suchak K, et al. Tumour-Infiltrating Lymphocytes Predict for Outcome in HPV-Positive Oropharyngeal Cancer. Br J Cancer (2014) 110(2):489-500. doi: 10.1038/ bjc.2013.639

79. King EV, Ottensmeier CH, Thomas GJ. The Immune Response in HPV(+) Oropharyngeal Cancer. Oncoimmunology (2014) 3(1):e27254. doi: 10.4161/ onci.27254

80. Näsman A, Andersson E, Marklund L, Tertipis N, Hammarstedt-Nordenvall L, Attner P, et al. HLA Class I and II Expression in Oropharyngeal Squamous Cell Carcinoma in Relation to Tumor HPV Status and Clinical Outcome. PLoS One (2013) 8(10):e77025. doi: 10.1371/journal.pone.0077025

81. Vu HL, Sikora AG, Fu S, Kao J. HPV-Induced Oropharyngeal Cancer, Immune Response and Response to Therapy. Cancer Lett (2010) 288 (2):149-55. doi: 10.1016/j.canlet.2009.06.026

82. Brandwein-Gensler M, Teixeira MS, Lewis CM, Lee B, Rolnitzky L, Hille JJ, et al. Oral Squamous Cell Carcinoma: Histologic Risk Assessment, But Not Margin Status, Is Strongly Predictive of Local Disease-Free and Overall Survival. Am J Surg Pathol (2005) 29(2):167-78. doi: 10.1097/01.pas.0000149687.90710.21
83. Wagner S, Wittekindt C, Reuschenbach M, Hennig B, Thevarajah M, Würdemann N, et al. CD56-Positive Lymphocyte Infiltration in Relation to Human Papillomavirus Association and Prognostic Significance in Oropharyngeal Squamous Cell Carcinoma. Int J Cancer (2016) 138 (9):2263-73. doi: 10.1002/ijc.29962

84. Kong CS, Narasimhan B, Cao H, Kwok S, Erickson JP, Koong A, et al. The Relationship Between Human Papillomavirus Status and Other Molecular Prognostic Markers in Head and Neck Squamous Cell Carcinomas. Int J Radiat Oncol Biol Phys (2009) 74(2):553-61. doi: 10.1016/j.ijrobp.2009.02.015

85. Yao Y, Yan Z, Lian S, Wei L, Zhou C, Feng D, et al. Prognostic Value of Novel Immune-Related Genomic Biomarkers Identified in Head and Neck Squamous Cell Carcinoma. J Immunother Cancer (2020) 8(2):e000444. doi: 10.1136/jitc-2019-000444

86. Krupar R, Robold K, Gaag D, Spanier G, Kreutz M, Renner K, et al. Immunologic and Metabolic Characteristics of HPV-Negative and HPV-Positive Head and Neck Squamous Cell Carcinomas Are Strikingly Different. Virchows Arch (2014) 465 (3):299-312. doi: 10.1007/s00428-014-1630-6

87. Welters MJP, Ma W, Santegoets S, Goedemans R, Ehsan I, Jordanova ES, et al. Intratumoral Hpvl6-Specific T Cells Constitute a Type I-Oriented Tumor Microenvironment to Improve Survival in HPV16-Driven Oropharyngeal Cancer. Clin Cancer Res (2018) 24(3):634-47. doi: 10.1158/1078-0432.CCR$17-2140$

88. Heusinkveld M, Goedemans R, Briet RJ, Gelderblom H, Nortier JW, Gorter A, et al. Systemic and Local Human Papillomavirus 16-Specific T-Cell Immunity in Patients With Head and Neck Cancer. Int J Cancer (2012) 131(2):E74-85. doi: $10.1002 / \mathrm{ijc} .26497$

89. Cillo AR, Kürten CHL, Tabib T, Qi Z, Onkar S, Wang T, et al. Immune Landscape of Viral- and Carcinogen-Driven Head and Neck Cancer. Immunity (2020) 52(1):183-99.e9. doi: 10.1016/j.immuni.2019.11.014

90. Parikh F, Duluc D, Imai N, Clark A, Misiukiewicz K, Bonomi M, et al. Chemoradiotherapy-Induced Upregulation of PD-1 Antagonizes Immunity to HPV-Related Oropharyngeal Cancer. Cancer Res (2014) 74(24):7205-16. doi: 10.1158/0008-5472.CAN-14-1913

91. Lyford-Pike S, Peng S, Young GD, Taube JM, Westra WH, Akpeng B, et al. Evidence for a Role of the PD-1:PD-L1 Pathway in Immune Resistance of HPV-Associated Head and Neck Squamous Cell Carcinoma. Cancer Res (2013) 73(6):1733-41. doi: 10.1158/0008-5472.CAN-12-2384

92. Schoenfeld JD, Gjini E, Rodig SJ, Tishler RB, Rawal B, Catalano PJ, et al. Evaluating the PD-1 Axis and Immune Effector Cell Infiltration in Oropharyngeal Squamous Cell Carcinoma. Int J Radiat Oncol Biol Phys (2018) 102(1):137-45. doi: 10.1016/j.ijrobp.2018.05.002

93. Oliveira-Costa JP, de Carvalho AF, da Silveira GG, Amaya P, Wu Y, Park KJ, et al. Gene Expression Patterns Through Oral Squamous Cell Carcinoma Development: PD-L1 Expression in Primary Tumor and Circulating Tumor Cells. Oncotarget (2015) 6(25):20902-20. doi: 10.18632/oncotarget.3939

94. Kim HS, Lee JY, Lim SH, Park K, Sun JM, Ko YH, et al. Association Between Pd-L1 and HPV Status and the Prognostic Value of PD-L1 in Oropharyngeal Squamous Cell Carcinoma. Cancer Res Treat (2016) 48(2):527-36. doi: $10.4143 /$ crt.2015.249

95. Patel J, Levy D, Nguyen S, Knochelmann H, Day TJH. Impact of PD-L1 Expression and Human Papillomavirus Status in Anti-PD1/PDL1 Immunotherapy for Head and Neck Squamous Cell carcinoma-Systematic Review and Meta-Analysis. Head Neck (2020) 42(4):774-86. doi: 10.1002/ hed.26036

Conflict of Interest: The authors declare that the research was conducted without any commercial or financial relationships that could be construed as a potential conflict of interest.

Copyright $\odot 2021$ Wang, Zhao, Zhang, Zhang, Zheng, Liu, Liu, Meng, Xin and Jiang. This is an open-access article distributed under the terms of the Creative Commons Attribution License (CC BY). The use, distribution or reproduction in other forums is permitted, provided the original author(s) and the copyright owner(s) are credited and that the original publication in this journal is cited, in accordance with accepted academic practice. No use, distribution or reproduction is permitted which does not comply with these terms. 